\title{
La crónica, el género literario del periodismo que merece sobrevivir
}

\section{The chronicle, the literary genre of journalism that deserves to survive}

\author{
Dennys Jordán Correa
}

Universidad Internacional del Ecuador, Ecuador

Autor para correspondencia: dejordancor@uide.edu.ec

Fecha de recepción: 01 de Septiembre de 2016 - Fecha de aceptación: 01 de Noviembre de 2016

Resumen: La escritura de géneros periodísticos requiere de técnicas y habilidades propicias e independientes al conocimiento teórico de la profesión. Se trata de la búsqueda de herramientas indispensables para lograr una narrativa lúdica que aborde temas urbanos enriquecidos con anécdotas, vivencias y el reflejo vivencial de las situaciones. A diferencia de otros géneros, la crónica resulta complicada porque hace una inmersión profunda en cada historia con el propósito de que el lector se identifique con ella; por eso, se vale de recursos literarios que sacudan la historia y muestren que toda coyuntura puede convertirse en eje principal. En la crónica, los periodistas se ponen en los zapatos de los personajes, oliendo, percibiendo, observando; este último aspecto implica la utilización de múltiples recursos sin alejarse de la realidad. No obstante, a pesar de ser un género enriquecedor, no todos los periodistas pueden narrar con éxito porque no hay escuelas destinadas a este fin; $y$, en los propios medios de comunicación, la sostenibilidad de estas historias es efímera, primero porque se necesita tiempo, investigación, intimidar con los personajes; en segundo lugar no hay espacio para la cantidad de caracteres que se producen y, finalmente, los lectores tampoco han creado la necesidad de su lectura; de allí la necesidad de gestionar herramientas necesarias para enseñar la escritura de este género y el deleite del mismo. Pero la crónica está destina a salvar del olvido a la tinta y el papel. Así lo reconoce Álex Grijelmo, el autor del libro "El estilo del periodista" en una entrevista concedida a diario El País en mayo pasado en donde da cuenta que si el periodismo impreso debe recurrir a la crónica y que se debe acentuar la presencia de este género ante la imposibilidad del medio impreso de competir con noticias con la radio, la televisión o la internet.

Palabras claves: periodismo; generos; técnicas; habilidades

Abstract: The writing of journalistic genres requires techniques and skills propitious and independent of the theoretical knowledge of the profession. It is the search for indispensable tools to achieve a playful narrative that addresses urban themes enriched with anecdotes, experiences and the experiential reflection of situations. Unlike other genres, the chronicle is complicated because it makes a deep immersion in each story in order for the reader to identify with it; For that reason, it uses literary resources that shake the history and show that any conjuncture can become main axis. In the chronicle, the journalists put themselves in the shoes of the characters, smelling, perceiving, observing; The latter aspect involves the use of multiple resources without departing from reality. However, despite being an enriching genre, not all journalists can successfully narrate because there are no schools designed for this purpose; And, in the media itself, the sustainability of these stories is ephemeral, first because it takes time, research, intimidation with the characters; Secondly, there is no room for the number of characters that are produced and, finally, readers 
have not created the need for their reading; Hence the need to manage the necessary tools to teach the writing of this genre and the delight of it. But the chronicle is intended to save the ink and paper from oblivion. This is acknowledged by Álex Grijelmo, the author of the book "The style of the journalist" in an interview given to El País newspaper last May where he says that if print journalism should resort to chronicles and that the presence of this journal should be accentuated Gender in the face of the inability of the printed media to compete with news with radio, television or the internet.

Key words: journalism; genres; techniques; skills

\section{Introducción}

\section{La crónica, el género de la riqueza del lenguaje}

Contar historias reales, en orden cronológico y utilizando recursos estilísticos del lenguaje para construir personajes y escenarios es el propósito de la crónica, el género periodístico libre por excelencia y considerado así por su capacidad para jugar con ritmos narrativos que diversifican la historia. El catedrático y periodista Gonzalo Martín Vivaldi, en el libro curso de redacción: teoría y práctica de la composición y del estilo, sostiene que la Crónica es, en esencia, un estilo híbrido, entre informativo y de opinión y que su característica esencial es la valoración del hecho, al mismo tiempo que se narra, es decir, imponiendo un estilo personal. "La crónica es, en esencia, una información interpretativa y valorativa de los hechos noticiosos, actuales o actualizados, donde se narra algo al propio tiempo que se juzga lo narrado". El diccionario de la RAE, señala que crónica es una palabra que proviene del lat. chronǐca, y este

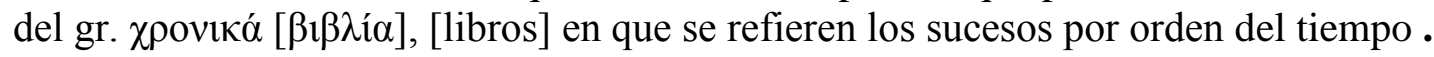

Este género implica un proceso de elaboración más complejo que la noticia. La extensión es el aspecto primordial que influye así como también la cantidad de hechos que confluyen de manera simultánea a través de un enfoque periodístico. Elaborar una crónica exige una investigación exhaustiva previa y, posterior, una redacción que despliega recursos narrativos que la caracterizan como compleja y difícil de lograr. "Hay que captar la atención del lector desde la primera línea. Y ello se consigue con una apelación noticiosa, con una anécdota curiosa o llamativa o con un juicio acertado y convincente sobre el hecho que motiva la crónica".

A diferencia del reportaje, el autor (cronista) expresará su visión particular (subjetiva) de los hechos y para su escritura suele emplear técnicas lingüísticas, propias de la Literatura. Esto hace que el periodista cree un lenguaje rico en detalles, usando recreaciones de la realidad.

"La vida en la cárcel no sale gratis. Las 1.635 presas que viven en el penal, según datos de enero de la Secretaría de Gobernación, no tienen acceso ni siquiera a jabón para ducharse o lavar la ropa. En la cárcel todo se compra, y todo se vende". Crónica de un día de feria en una cárcel de mujeres mexicana". (Diario El País)

Estos atributos permiten recrear la realidad sin violar la veracidad de los hechos. También recoge la exigencia de que el periodista haya presenciado los acontecimientos y los narre. "Lo que transmite el cronista es de primera mano, lo que ha visto y oído. (...) cuando no es posible mantener el supuesto de la presencia viva del cronista en las escenas que se relatan, será arte 
mayor hacerlo de modo indirecto para crear así una ilusión de realidad”, sostiene Miriam Rodríguez Betancourt, catedrática de la universidad de Cienfuegos en Cuba.

Conmover y hacer que el autor experimente la sensación de vivencia es el propósito principal de este género; por eso, el relato está impregnado de imaginación, no para nadar en la ficción sino para recrear un mundo a partir de lo que sucede en un momento dado. Es decir, la crónica permite entender en qué mundo vive; si se trata de un conflicto bélico, narrará el sufrimiento de las víctimas con tal habilidad narrativa que el lector será capaz de experimentar y comprender porque el escritor lo transportará al lugar de los hechos.

Juanita León García, periodista colombiana, autora de La Silla Vacía, un medio informativo e interactivo para las personas interesadas en la actualidad política del vecino país, los cronistas retratan lo que sucede en un momento determinado de la historia. "Eso le permite a la gente entender en qué país vive. En una guerra les permite a las víctimas narrar su sufrimiento, estar seguras de que no caerá del todo en el olvido. Para los victimarios es a veces el único castigo. Aunque también a través de las crónicas uno entiende que las cosas siempre están llenas de matices. Eso es bueno porque evita soluciones simples y que no sirven para nada".

"Arcelio patea el balón y una nube de polvo colorado se levanta a la altura de sus rodillas. Gol, claro. Aunque fue una pegada maravillosa, celebra sin sonreír y patea de nuevo. Esta vez la pelota se va desviada del arco. Un niño flaco de unos doce años corre detrás y la regresa con un golpe”. (Fundación para un Nuevo Periodismo Iberoamericano)

El español Alex Grijelmo, manifiesta que "la crónica toma elementos de la noticia, del reportaje y del análisis. Se distingue de los dos últimos en que prima el elemento noticioso, y en muchos periódicos suele titularse efectivamente como una noticia (salvo las crónicas taurinas y deportivas, en que se emplean por lo general tipografías diferentes) y se distingue de la noticia porque incluye una visión personal del autor". Todos estos elementos hacen que el género sea considerado difícil de dominar y, por ende uno de los menos apetecidos para utilizar por los profesionales del oficio periodístico.

El periodista y escritor argentino Martín Caparrós, quien publicó en el 2015 su libro 'Lacrónica', un compendio de sus reflexiones sobre el periodismo y sus mejores trabajos de los últimos 30 años, asegura que la crónica logra buenos resultados. No porque sea la mejor herramienta para contar una historia, sino porque es la más eficiente.

Mirar también es poner en acción tus ideas sobre el mundo, adónde vas a dirigir la mirada, qué es lo que vas a querer ver, qué esfuerzos vas a hacer... y eso tiene que ver con tu concepción del mundo. También detrás de los ojos hay una serie de herramientas que se ponen en acción para mirar. Yo hago esa diferencia entre ver y mirar. Ver es esa situación supuestamente involuntaria en la que a uno le entran imágenes que voluntariamente no quiere. En cambio, mirar es una acción voluntariamente decidida, en la que uno está focalizándose en ciertas cosas, insisto, con herramientas de los dos lados de los ojos.

No diría que es la mejor. Es un instrumento que muchas veces logra buenos resultados y es el que a mí me gusta más, pero hay muchas otras formas de contar el mundo, por lo menos tan 
interesantes y tan eficaces como una buena crónica. En los medios digitales se están utilizando con éxito otras fórmulas y otras narrativas. Dentro de diez o veinte años estas nuevas herramientas serán infinitamente mejores que la crónica.

John lee Anderson, periodista estadounidense, especializado en temas latinoamericanos, aborda la crónica como una manera de contar historias con mucho tino para que el autor no caiga en la alabanza ni en el repudio; para esto, es necesario dejar que los lectores formen su propio juicio, contrastando las opiniones. Este relato requiere describir personajes, pero usando múltiples ángulos para la narración acerque al lector. Es necesario que el lector no descarte el contexto porque éste humaniza el relato y, a su vez, considerará las variables: qué, quién, cómo, cuándo, dónde para situar la acción concreta y mostrar al lector por qué se escogió ese punto de la historia. A esto se denomina ambientación tridimensional del personaje: mostrar dónde vive, dónde trabaja, qué hace en sus ratos libres, qué dicen sus amigos de él, qué opinan su pareja y sus familiares, mostrar su rostro y sus gestos.

"No hay que compartirlo todos: hay que escoger los más significativos y ahorrarle al lector los que hacen parte del proceso mecánico de la reportería. Otros nudos que pueden afectar el tono narrativo y que también deben suavizarse son las estadísticas (la información seca y utilitaria) para que la crónica no pierda esa virtud de leerse como un cuento. Pero en lo que la crónica no debe parecerse a un cuento es en el énfasis sugestivo o elíptico de este. Si la crónica deja una sensación de misterio, de algo desconocido, con huecos y claroscuros que debe rellenar demasiado el lector, entonces queda la impresión de que no le ha dado toda la información, o de que el periodista no ha sido lo suficientemente minucioso y exhaustivo". .

\section{Espacio, enemigo de la crónica}

La crónica tiene una doble finalidad: recrear un hecho a través de un texto narrativo y valorar dichos acontecimientos. Esta narración de estilo creativo no se limita a la simple transcripción e interpretación de un acontecimiento, sino al análisis de la narración. La capacidad para crear valoraciones desplegadas en la riqueza del lenguaje narrativo es una de las características más complejas de lograr. Y, esto, ha hecho del género, uno de los más esquivos; son pocos los cronistas que deleitan al público lector con sus historias y más limitados los espacios periodísticos que los medios de comunicación impresa le otorgan a la crónica, precisamente, por su falta de autores y particular estilística.

En Ecuador, la crónica se reduce a espacios contados los fines de semana, fechas en las que aparecen retratadas las historias cotidianas en los principales medios impresos a nivel nacional. Diario El Telégrafo, en su artículo Y para qué sirve la crónica... señala que "los cronistas confiesan su frustración ante la censura, el fenómeno actual del tabloidismo, la modernidad como enemiga del género, la complejidad de hacerse entender, la capacidad de captar la realidad a través de un "tercer ojo", y plasmar la investigación recordando cada detalle, sin perder el estilo y manteniendo al margen a la ficción"; y para evidenciar su titular, recrea un texto con algunos cronistas internacionales, quienes dan su apreciación:

“Cuál cree usted que es el enemigo de la crónica? Ramón Jimeno: El enemigo de la crónica es la modernidad; va asociada a escasez de tiempo y a un hábito que se está 
desarrollando en la nueva industria del entretenimiento en las nuevas generaciones que es el de consumir cosas muy rápidas y ligeras; se ha vendido la falsa idea de que la gente en la sociedad moderna no tiene tiempo para leer un periódico, un buen artículo, un buen libro, una buena crónica. Y se ve obligada a mirar noticias en quince minutos. Eso es una trampa para el ser humano, porque el ser humano necesita comer despacio, la comida rápida es para cuando uno tiene afán (apuro), pero no todos los días se puede estar comiendo fast food. También existe el arte basura, pero el individuo debería ir a una galería, a un museo, se tiene que conocer a los grandes pintores, hay que leer noticias rápidas, pero, también hay que leer crónica. La crónica es enemiga de la industria de los medios masivos de comunicación que necesita cosas muy baratas, rápidas y desechables; una buena crónica requiere buena investigación, un trabajo de campo, extenso, calmado, requiere una persona preparada con muchos conocimientos, habilidades para conocer personas y saber tratarlas e implica habilidades para escribir; entonces una buena crónica se demora un mes, dos meses, seis meses y ¿cuánto vale eso? No hay ningún medio. Como resultado contratan a un muchacho de dieciocho años para que haga una nota de treinta segundos y eso lo pasan como crónica: ese es el enemigo. No es la inmediatez, sino la estupidez de los dueños de la industria del periodismo mundial que necesitan una utilidad grande, rápida y con baja inversión".

El ya citado, Martín Caparrós da cuenta que el periodismo actual hace de la crónica, un resumen o una cita en su portada: "Estoy harto de la palabra crónica: me tiene cansadísimo. Asegura que su intención es "deshacer la facilidad" con la que a su juicio se habla de las crónicas. "Es un juego y si uno se tiene que poner a explicar los juegos está perdido".

La crónica es considerada como el género periodístico que mayor riqueza posee. Sin embargo, cada día los medios de comunicación limitan su espacio; y, por ende, la manera de abordar historia y en disfrutar de esta narrativa. El diario limeño La República, en su artículo "La crónica periodística debe ser la diferencia de un medio", señala que la versión impresa de La República no tiene mucho espacio para las crónicas y consulta con el periodista Juan Carlos Meneses sobre esta situación. Él da su versión, acotando que: “Quisiera que todos los diarios tengan más crónicas y reportajes, pero tampoco se puede dejar de lado que los diarios son empresas que buscan públicos con diferentes gustos y tienen que satisfacerlos. Es por eso que un periódico debe tener espacio para todo tipo de géneros que le dan variedad y sentido al medio. La crónica periodística debe ser la diferencia de un medio".

\section{Una propuesta de aprendizaje}

¿Las crónicas que publican los medios de comunicación se convierten en herramientas de enseñanza-aprendizaje para las generaciones de periodistas que están en proceso de formación? Lamentablemente la interrogante tiene respuesta negativa porque en los diarios la cabida para este género es limitada; $y$, sin embargo, estos deberían ser los principales aliados para la enseñanza universitaria. Entonces ¿es pertinente asignar más espacios dentro de los medios de comunicación para este género periodístico? ¿Qué estrategias podrían desarrollar los estudiantes de periodismo para la escritura de crónicas?

La Fundación de Gabriel García Márquez para un Nuevo Periodismo Iberoamericano (FNPI) realiza, desde el 2012, el programa de formación para profesionales de Cartagena 
(Colombia) y de América Latina, Periodismo al Barrio cuyo objetivo es desarrollar un programa formativo para los profesionales. En el año 2015, el proyecto abordó la crónica como género narrativo para enfrentar las historias que se producen en el barrio Nelson Mandela. Para ello, tomaron 12 participantes que buscaron las mejoras historias del sitio, situado en las afueras de Cartagena y conformado por más de 40.000 habitantes, víctimas de la guerrilla y los paramilitares. De allí se extrajo trabajos que se convierten en modelos fidedignos del arte de la composición profunda a través de información, descripción y narración pura.

Anderson, quien se inició como periodista en Perú, en 1979, ha desarrollado una escuela sobre la forma de escribir perfiles y crónicas. Se desempeña como maestro y miembro del Consejo Rector del Premio Gabriel García Márquez de Periodismo y durante el taller evidenció el aprendizaje a través de un manual que resume tres puntos imprescindibles para escribir una crónica.

Primero hay desprenderse del bagaje, lo que implica abandonar los prejuicios del periodista y hacer empatía con la gente "Hay que convencer a los que te miran para derrotar el recelo. El respeto por la gente humilde debe ser genuino". En segundo lugar, se debe profundizar en los lugares comunes "Con los poderosos casi todo vale pero con los pobres hay que ser más sensible y hay cosas que no deben ir en tu texto si sabes que los pones en riesgo". Finalmente, se debe tener cuidado con los detalles "Lo primero que sentí en Cartagena al traspasar las murallas donde termina el decorado turístico, fue el olor a desagüe. Hay que estar pendiente de los sentidos para aterrizar con una mirada fresca y nueva a los temas. Utilizar la mirada no solo para ver sino también prestar atención a los olores o los sonidos para ver lo que nos dicen. El detalle lleva a la profundidad".

Para Vanesa Robles, ganadora del Premio Jalisco de Periodismo, la crónica debe ganar espacio en los diarios de Jalisco y el mundo. En el artículo Los periodistas reivindican espacio para la crónica, argumenta que "La crónica es eso que nuestros periódicos hacen cada vez menos...", haciendo referencia a la inmediatez que brindan los medios de comunicación, cerrando los espacios para analizar y entender la realidad.

Pero ¿cómo logarlo? El sociólogo, filósofo y teórico de la comunicación Jürgen Habermas propone que en una sociedad democrática los medios de comunicación cumplen un papel de cuarto poder cuando recaban opiniones de los expertos para proporcionar a los ciudadanos una información actualizada, detallada y fidedigna sobre todos los temas que suscitan la preocupación pública. De esta manera, se asocia que la crónica, independientemente de sus características que involucran la emisión de juicios de valor, debería abordar su imparcialidad. Por su parte, F. Fraser Bond, en su libro Introducción al periodismo: estudio de cuarto poder en todas sus formas, describe a la crónica como una escueta información. Esto se refiere al tratamiento que algunos diarios asignan cuando usan la frase "crónica de nuestro corresponsal", limitándola a un trabajo meramente informativo. Por ende, propone que "lo que distingue la verdadera crónica de la información, es precisamente el elemento personal que se advierte, ya porque va firmada generalmente, ya porque el escritor comenta, amplía y ordena los hechos a su manera; ya porque, aunque la crónica sea informativa, suele poner en ella un lirismo sutil, una dialéctica y un tono característico que vienen a ser el estilo de su esencia misma". 
En Ecuador los diarios guayaquileños tienen espacios limitados para la crónica periodística y esta limitación se fundamenta en dos matices. El primero la falta de espacio que existe en los rotativos, en donde se prefiere dar cabida a la farándula, el deporte o los sucesos, considerados por los departamentos de Marketing de los mismos diarios como las noticias que más lectores tienen; y el segundo la poca preparación que existen en las universidades para dotar a sus estudiantes de las armas que requiere un periodista para contar una buena historia que enganche al lector.

El veterano periodista español Fernando Jáuregui, no solo se observa una falta de investigación y de periodismo presencial. Si también una generalización de los "redactores Google" y una relevancia excesiva de las redes sociales. Además, lamenta la confusión con el "periodismo de espectáculo" y la presencia de "señores que influyen cada día más" en las informaciones de los medios, "desde los políticos hasta los comerciales", de forma que "el espacio que queda para el periodismo es muy poco, y entre esa limitación está a crónica. Qué no solo carece de espacio, sino también de gente proba que la escriba.

En El Telégrafo, por ejemplo, se pide a los periodistas escribir crónicas periodísticas al menos una vez por semana. Pero no se los desliga del diarismo. De la rueda de prensa, del informe, del boletín y de la declaración. Eso le genera que en su agenda la prioridad se la noticia; esa misma noticia que al momento de publicarla es un producto conocido por medio de las redes sociales. Además cuando se genera un espacio en el diario físico para la crónica este es muy proclive a desaparecer, porque la crónica a más de generar un trabajo mucho más forzado terminan siendo temas de poca lectoría, si el enfoque no es el apropiado y los personajes no generan interés.

La historia de un artesano dedicado a trabajar en un astillero muy bien contada, y narrada por un periodista de trayectoria puede tener menor impacto que una crónica de farándula hecha por un principiante a un personaje conocido de la prensa rosa. El medidor del número de visitas en las páginas web de los diarios resulta toda una autoridad y hasta una dictadura que determina qué nota se ganó la aceptación del público. Y en muchos casos la crónica no es el género que mayor seguidor tiene.

La otra falencia radica en la falta de periodistas especializados en crónicas. Sin duda el género que requiere, no solo de mayor atención de los periodistas sino el estar muy bien informado y tener una buena pluma, esto va de la mano con una buena ortografía, concordancia y sintaxis.

Para el periodista Alberto Salcedo Ramos, un cronista es alguien que investiga como los periodistas y escribe como los escritores. Convierte la realidad informativa en asombro. La definición deja claro que no todos los periodistas están en capacidad de contar una buena historia, por más que la definición básica de la crónica sea contar un hecho de forma cronológica. De ahí que los diarios en el país no tienen el suficiente número de cronistas y que muchas historias no han sido bien contadas.

\section{Conclusiones}


La crónica aborda una realidad a través de la interpretación y valoración de hechos actuales; no admite comentarios sino relatos puros a través de un estilo libre (no tiene esquemas como en la noticia) y que presente una visión clara de lo que sucede.

Como género periodístico, la crónica es digna de estudiar porque su técnica (casi improcedente, ya que el buen cronista impone su propia técnica) maneja un estilo particular.

Su trascendencia radica en la influencia en la opinión pública porque es a través de este relato que se forma la propia sentencia de las cosas o hechos, reflejando su cualidad crítica. Sin embargo, no todo periodista está apto para su consagración como cronista y ante la escasa consideración del género en los medios impresos y la inexistente escuela de cronistas en el mundo y específicamente en Ecuador, resulta paradójico preguntar ¿cómo aprender su estilo? De allí la importancia de replantear estas consideraciones para asumir que no queda otra opción que es volcar la responsabilidad de formación a los propios medios y a las Facultades de Periodismo para formar desde las aulas las mejores lecciones de la narrativa como género.

\section{Bibliografía}

Anderson, J. (febrero de 2015). Fundación Nuevo Periodismo Iberoamericano. Obtenido de Cronica en el Nelson Mandela: http://cronicaennelsonmandela.fnpi.org/

El Informador. (16 de diciembre de 2013). Obtenido de Periodistas reinvindican espacio para la crónica: http://www.informador.com.mx/cultura/2013/503000/6/periodistas-reivindicanespacio-para-la-cronica.htm

Flores, M. (2014). Clases de periodismo. Obtenido de http://www.clasesdeperiodismo.org/crnicaperiodstica-teora_02/

Gimenez, V. (2012). Cinco consejos para escribir una buena crónica periodística

Grijelmo, A (2016): "El periodismo en papel no morirá"

Grijelmo, A. (2009). El Estilo del periodista. Taurus: España. http://ijnet.org/es/blog/cinco-consejos-para-escribir-una-buena-cr\%C3\%B3nicaperiod\%C3\%ADstica http://www.elmundo.es/baleares/2016/05/25/5745524ee5fdea503e8b45f7.html http://www.europapress.es/nacional/noticia-fernando-jauregui-advierte-periodismomuriendo-pide-refundacion-profesion-20150308123550.html

Infoamérica. (s/f.). Obtenido de http://www.infoamerica.org/teoria/kayser1.htm

Jáuregui, F (2016).: "El periodismo está muriendo, si es que no está ya muerto"

Limitaciones y posibilidades de la crónica: recomendaciones finales de Jon Lee Anderson. (mayo de 2012). Obtenido de Taller de Periodismo y Literatura: crónicas de la Barranquilla de 
García Márquez,: http://reddeperiodismocultural.fnpi.org/2012/05/30/limitaciones-yposibilidades-de-la-cronica-nuevas-recomendaciones-de-jon-lee-anderson/

Paucar, C. (5 de septiembre de 2011). Diario La República. Obtenido de http://www.clasesdeperiodismo.com/2011/09/05/\%E2\%80\%9Cla-cronica-periodisticadebe-ser-la-diferencia-de-un-medio $\% \mathrm{E} 2 \% 80 \% 9 \mathrm{D} /$

Real Academia Española. $\quad$ (s.f.). Obtenido de http://lema.rae.es/drae/srv/search?key=cr\%C3\%B3nica

Rodríguez, D. G. (3 de mayo de 2013). Y para qué sirve la crónica... El Telégrafo.

Rodriguez, M. (2009). La crónica periodística: un género tan polémico como imprescindible. La Habana. Obtenido de Unión de Periodistas de Cuba en Cienfuegos. .

Sala de prensa. (2010). "Sofismas de distracción". Obtenido de Web para profesionales de la comunicación iberoamericanos.

Vivaldi, M. (2006). Curso de Redacción teórica y práctica. España: Paraninfo. 